Portland State University

PDXScholar

Summer 2021

\title{
A Tale of Two Narratives: The Role of Storytelling in Racial Dialogue
}

Lane Cooper

Follow this and additional works at: https://pdxscholar.library.pdx.edu/honorstheses

Part of the Multicultural Psychology Commons, Peace and Conflict Studies Commons, and the Social Justice Commons

Let us know how access to this document benefits you.

\section{Recommended Citation}

Cooper, Lane, "A Tale of Two Narratives: The Role of Storytelling in Racial Dialogue" (2021). University Honors Theses. Paper 1143.

https://doi.org/10.15760/honors.1174

This Thesis is brought to you for free and open access. It has been accepted for inclusion in University Honors Theses by an authorized administrator of PDXScholar. Please contact us if we can make this document more accessible: pdxscholar@pdx.edu. 
Running Head: A TALE OF TWO NARRATIVES

A Tale of Two Narratives: The Role of Storytelling in Racial Dialogue

by

Lane Cooper

An undergraduate honors thesis submitted in partial fulfillment of the requirements for the degree of

Bachelor of Science

in

University Honors

and

Psychology

Thesis Advisor

Tom Hastings

Portland State University

2021 


\title{
A TALE OF TWO NARRATIVES
}

\begin{abstract}
Storytelling is a tactic often used in intergroup dialogues as a means for highlighting the human aspect of intractable identity-based conflict. In the U.S., racial dialogues are a popular method for addressing racism and exposing the systems that enable its survival. However, stories told by People of Color during these dialogues are often met with denial, dismissiveness, and even complete silence by their White counterparts. This then leads to cognitive and emotional distress for the tellers and a lack of action from the listeners. Using a theoretical analysis, this paper reviews the narrative conflict around racism and applies psychological research and theories to explain why this backlash might be happening. First, this paper dissects the overarching dominant and counter narratives that give shape to this intergroup conflict. Then, psychological concepts such as Racial Identity Development and Cognitive Dissonance Theory are applied to show how these clashing narratives might inflame conflict and skew expectations during racial dialogue. The implications regarding dominant and counter narrative, and the possibility of a shared narrative, are discussed. This paper also highlights the importance of honoring the narratives of People of Color and suggests ways in which dialogic practitioners (and White people in general) can work to mitigate White resistance.
\end{abstract}




\section{A TALE OF TWO NARRATIVES}

The events of 2020 surrounding the death of George Floyd and the subsequent uprising of the Black Lives Matter movement have highlighted the undercurrent of racism and the need for the ability to talk openly and honestly about race in the United States. People of Color and their allies have taken to the streets and flooded the internet with testimony of the oppression and race-based hardships that have impacted their lives. The call to amplify the voices of Black, Indigenous, and People of Color (BIPOC) has been ringing loudly across the nation. In the world of peacemaking this call is nothing new. As Johan Galtung states, "one of the main goals for peace activists is to facilitate and amplify the voices of those who are not being heard" (as cited in Senehi, 2002, p. 42). For decades, peace activists, psychologists, and educators have been trying to figure out how to understand and resolve intractable identity-based conflicts such as these. One way to do that is through the use of dialogues.

Overall, dialogic practices have been a helpful tool in dealing with and resolving intergroup conflict. For example, Rothman (1997) found promising results when applying his dialogue and reconciliation process (ARIA) workshops in the Jerusalem Peace Initiative. Both Israeli and Palestinian participants were able to talk openly about the conflict over Jerusalem, and by the end of the workshop, even came proposed concrete policies to help advance cooperative living (Rothman, 1997). In the United States (U.S.), the overarching intractable conflict is not centered around territory, but rather it's centered around race. Racial dialogues are conversations between people of different racial, ethnic, or cultural backgrounds designed to address race, racism, and systemic inequality (Miller \& Donner, 2000). These dialogues can be structured (i.e. diversity trainings, anti-racism workshops, classroom discussions, etc.) or unstructured (i.e. conversations between friends/families/neighbors, etc.) (Sue, 2013), but for the purposes of this paper I will be focusing on structured/facilitated dialogues since these are able to 


\section{A TALE OF TWO NARRATIVES}

provide tangible data. These dialogues are designed to offer a safe space for people of different racial backgrounds to share personal experiences, air grievances, and situate oneself in the larger social system of oppression and privilege (Gurin et. al., 2013). It is hoped that these dialogues will help to bridge differences, improve understanding and cooperation between groups, and ultimately lead to social justice-based action (Nagda et. al., 2007; Miller \& Donner, 2000; DiAngelo, 2004). Often, these dialogues (structured or otherwise) amplify the voices of Black, Indigenous, and People of Color (BIPOC) through the use of storytelling.

Storytelling is a universal and uniquely human activity. Many cultures use stories to relay important information on how to live and behave. They hold great cultural significance and often contain clues as to the beliefs, values, norms, customs, rules, and expectations of a given community or society (Carter-Black, 2007). For example, the Coyote is the subject of many legends in Native American cultures across the U.S. Coyote is a mythological creature and often plays the role of the trickster - his antics get him into trouble, but his cleverness often gets him out. In several of the West Coast tribes, Coyote is also responsible for "bringing fire to the people, teaching them the arts of civilization, and helping to shape the world for their benefit" ("Native American Legends: Coyote (West Coast and Northwestern)", n.d.). It is stories and legends like these that give us clues on how to behave and provide explanations regarding social order and conditions. Stories provide a foundation for us to order our world and construct a sense of reality (Gates, 1989). Since we use these underlying messages as moral and behavioral guidelines, stories also serve as a bridge to understand the individual, the larger systemic social arrangements, and how the individual functions within those arrangements (Bell, 2003). By listening to the stories and narratives shared by People of Color in racial dialogue, we can better understand how these stories of struggle, resilience, and survival can help to illuminate the 


\section{A TALE OF TWO NARRATIVES}

enduring nature of racism and expose the system that enables its survival. Several scholars have found positive outcomes of storytelling, particularly for the tellers. Senehi (2002) argues that storytelling is a means of resistance, comfort, and survival, and therefore may have a therapeutic effect on those who share their experiences. Telling these stories within this context may serve to empower People of Color and amplify the ways in which race has impacted their lives. This is supported by a recent study that examined the effectiveness of the "Restorative Listening Project" - a set of structured cross-racial dialogues designed to address the rapid gentrification of the Albina neighborhood in Portland, Oregon (Drew, 2012). Drew (2012) found that the 'knowledge presenters' - African Americans who shared their stories - found great value in being able to openly express their experiences as members of Portland's "Black community." Even though most knowledge presenters shared these stories in the hopes to educate White people, many also reported that they learned something new, attained a clearer understanding of how racism operates, and even began to feel the effects of racial healing. As one research participant put it, "It is healing for us to acknowledge the pain. It's not important whether or not the White people listen or accept what we say. It is important that we tell these stories for our own healing. Instead of holding this stuff inside our whole lives, with no outlet, causing all kinds of mental and physical anguish" (Drew, 2012, p. 110). Testimonies such as these speak to some of the positive side effects of storytelling. However, even though revealing oneself and one's social suffering through this kind of authentic storytelling can have an empowering or therapeutic effect, it can often produce cognitive and emotional turmoil when stories are met with resistance (Sue, 2013).

In examining the use of storytelling in a series of anti-racism workshops, Srivastava and Francis (2006) found that when People of Color shared their personal stories of racial struggle, 


\section{A TALE OF TWO NARRATIVES}

White people often became defensive, denied reality, or derailed the conversation altogether. Thus, they argued, that this inability for White people to listen to and accept counter narratives not only exacts a heavy toll on People of Color, but also detracts from the overall goal of the dialogue: systemic change (Srivastava \& Francis, 2006). Similarly, while exploring the psychology of racial dialogues in higher education, Sue and his colleagues uncovered some startling patterns regarding the convergence and divergence of perspectives around racial narratives. They found that Students of Color (Sue et. al., 2009) and Faculty of Color (Sue et. al., 2011) unanimously reported that racial dialogues were often sparked by racial microaggressions. When these microaggressions were confronted, both White students and Students of Color felt conflicted about whether or not to speak up, though often for very different reasons. Students of Color felt the need to share their personal stories in an effort to educate White students. However, these stories were often met with (a) silence or refusal to participate; (b) diverting conversation to a safer topic; (c) diluting or dismissing the importance of the topic (i.e. gaslighting); (d) instituting restrictive rules for how the dialogue should take place; (e) speaking about race from a global perspective or as a bystander rather than as an active participant; and/or (f) tabling the discussion with little intention of follow-up (Sue, 2013). This appeal to defend and deflect the stories is present in White students even when confronted with second-hand racial narratives in literature and textbooks (Trainor, 2005). These disengaging behaviors can not only enact heavy toll on the tellers but may also lead to unaddressed feelings and emotional roadblocks for all parties involved in the dialogue (Sue, 2013). Since the goal of these dialogues are often to enhance understanding, bridge differences, and create lasting social change, these findings are concerning. Why is this happening? Why is it that storytelling, while effective for overall conflict, is being met with such backlash during racial dialogue? This paper will explore 


\section{A TALE OF TWO NARRATIVES}

these questions and contributing factors to how individuals may react to and be impacted by discussions around race and racism.

\section{Analysis}

This section will begin by exploring the aspects of dominant and counter narrative and the role that power and privilege play in shaping these narratives. I will then more closely examine one's internal processes (i.e., cognitions, development, personal awareness) and how these processes are interconnected with and impact interpersonal/social interactions, particularly those with individuals who come from different backgrounds and experiences from one's own. Sue's (2013) Racial Identity Development Model and Helms' (1984) White identity Development Model will serve as the backdrop of this examination. I will also touch upon McGrath's (2017) theory of Cognitive Dissonance - a common affliction felt by both White and People of Color during identity development - to highlight storytelling's effect on cognitive conflict. By drawing from both conflict resolution research and psychological theories, I will ultimately show how storytelling, while moderately effective, can inflame these interpersonal/social interactions and even have an undue negative impact on the reception of racial dialogue.

\section{Dominant and Counter Narratives}

In her study on racial attitudes, Bell (2003) noticed an interesting pattern emerge from her interviews: storytelling. Even though they were not directed to do so, most participants (both White and BIPOC) told stories to make a point or illustrate their experiences with racism. Within these stories, themes began to emerge which, Bell suggests, hold important clues as to why racial attitudes differ. These stories help to shape our worldviews and where we are regarding our racial identity. I would like to take this a step further and suggest that differences within these 


\section{A TALE OF TWO NARRATIVES}

stories and within these stages of development are contributing factors to blockages in racial dialogue.

Through critical discourse analysis, scholars have suggested that within racial dialogue there are often two kinds of talk - "White talk" and "back talk" (Bell, 2003; McIntyre, 1997; Sue, 2015). White talk exemplifies the public transcript (dominant narrative), which serves to "insulate White people from examining their/our individual and collective role(s) in the perpetuation of racism" (McIntyre, 1997, p. 45). This is achieved by depicting the U.S. as progressive, meritocratic, and basically fair (Bell, 2003). White people can comfortably move through life without being challenged as a racial being. Conversely, People of Color experience life through the lens of race (Sue, 2015). Their "back talk" reflects a sense of differential treatment, insensitivity, attacks on one's sense of worth, and a constant air of danger and vulnerability (Bell, 2003). This counter narrative threatens to dismantle the illusion of a postracist society as it contradicts the 'good' and 'progressive' nature of the dominant White narrative. Since both narratives come into play in racial dialogue, we can see how this clash of realities may lead to misunderstanding, cognitive distress, and even backlash. It is also important to note the dynamics of power and privilege also play an important role in shaping these narratives.

In her exploration into storytelling as a peace process, Senehi (2002) argues that storytellers - with their ability to generate personal narrative - may be able to gain "relative control in the process of the social construction of meaning" (p. 44). The ability to construct meaning is a powerful tool. What is meant by this is that our social and cultural backgrounds and experiences shape and influence how we make meaning of ourselves, our social world, and our interactions with others. Our cultural identities, sociocultural and historical contexts, the ways in 


\section{A TALE OF TWO NARRATIVES}

which we are raised, and the values, attitudes, and beliefs that we develop are among contributing factors that impact how we engage in meaning making (i.e., how we interpret and feel about our social interactions and environment). These interpretations and feelings about our environment mold what we perceive to be "truth", and thus affect how we piece together and create meaning out of sedimented social conditions (Maines, 2000). However, as Bauman and Briggs (1990) point out, the access to and process of meaning-making is largely unequal, therefore, whoever has the power to tell stories also has the power to construct social meaning. In the context of the United States, White Americans have long held this power and, thus, the White narrative has become dominant. With this power also comes great privilege. Not only is this narrative privileged, but it also affords one privilege in how they interact and benefit from the world. Peggy McIntosh (1989) likens this privilege to an 'invisible knapsack', one that comes with all the maps, provisions, and tools one could need to thrive in U.S. society. Even though this privilege is often 'invisible' to those who have it, it can still manifest in a number of ways. For McIntosh (a White woman), having this knapsack meant that she was given a package of unearned assets such as the ability to apply for jobs, take out loans, or seek medical attention without worrying that her race will work against her; the ability to criticize authority without fear of retaliation; and the ability to easily find company and a sense of belonging with people who looked like her (McIntosh, 1989). These types of privileges are often not afforded to People of Color. Racism sets up a system in which People of Color often find themselves forced to "deal with people who do not look [them]" (Drew, 2012, p. 106) and do have to worry about their race working against them in a variety of ways (Bell, 2003). A Native American woman and social worker illustrates these differences in power and privilege in the following story:

"Last week... I was coming into the building and my supervisor was outside smoking a cigarette. My supervisor is a White male dressed in his suit and his tie. DSS 


\section{A TALE OF TWO NARRATIVES}

[Department of Social Services] has security now that are present in the building. So I start toward the elevator. Now I'm walking with my supervisor. He's White and my face is brown. The security guard says to me, 'Hey where are you going?' I said, 'Are you talking to me?' He says 'Yeah, you going to welfare?' So I said, 'Excuse me?' My supervisor says to me, 'You don't have to answer that question, he has no right to ask you that.' I said 'But you don't understand what the bigger picture is, that he thinks that People of Color are all going to welfare.' My supervisor said, 'No, that's not what it is about... He's just doing his job. He has to ask everybody.' I said, 'That's exactly what it's about."' (Bell, 2003, p. 13)

This story not only shows the power given to the two White males, but shows the privilege afforded to the White supervisor in that his whereabouts were not questioned, and he could openly challenge authority ('he has no right to ask you that') without being retaliated against. More importantly, this also shows the lack of power and privilege afforded to the Native American woman, in that her race was immediately equated to poverty and that this assumption was quickly dismissed by her White supervisor. The dynamics at play in this story reflect the overall essence of dominant and counter narratives. So, when counter narratives are presented, they may be immediately dismissed since they contradict and challenge the dominant narrative. It is interactions such as these that, intentionally or not, work to reinforce these narratives and shape our worldviews.

\section{Racial Identity \& Worldview}

A worldview is our own personal and unique way of viewing and relating to the world. In the world of storytelling, Carter-Black (2007) notes that "the structure and process of storying how stories are told, by whom, to whom, under what circumstances, and for what specific purpose - vary according to sociocultural prescriptions" (p. 32). In other words, our culture not 


\section{A TALE OF TWO NARRATIVES}

only influences what we share in our stories but also how we share those stories; two people can experience, interpret, and recount the same event in two very different ways simply because of their significant cultural differences. While race is a socially constructed concept, it still plays a significant role in one's worldview, particularly those from marginalized groups. A Person of Color's race or skin tone is constantly reinforced by how White people respond to them. Even though the dominant narrative works in favor of White people, the hidden messages are not lost on People of Color. There are many factors that could influence one's worldview. One important factor, especially in the U.S., is racial identity.

As we grow up and interact with those around us, we may begin to form questions about who we are and how we fit into the fabric of society. Even though everyone struggles with questions around identity, individuals from marginalized groups face a unique challenge: "they must also resolve conflicts related to their minority status, whether that be based on race, gender, sexual orientation, physical ability, or some other trait that makes them 'different' from the American mainstream" (Mio et. al., 2012, p. 202). Over the years, researchers noticed patterns in how different racial, ethnic, and cultural groups answered these questions and in how they formed personal identity. Identity development models highlight and give structure to this process. These models show how interpersonal and sociocultural factors may influence an individual's personal identity, and how one adjusts to those factors. (Mio et. al., 2012) While there are models for various kinds of racial, ethnic, and cultural groups (e.g., transgender, gay/lesbian, multiracial, women, specific ethnicities and races), for the purposes of this paper I will focus on the Racial and Cultural Development (R/CID) and the White Identity Development models. 


\section{A TALE OF TWO NARRATIVES}

$\mathrm{R} / \mathrm{CID}$ is often used as a reference for marginalized groups, and is defined as "a general model that covers all forms of cultural identity and addresses how one relates to oneself, to others of the same culture, to others of different cultures, and to the dominant group" (Mio et. al., 2012, p. 221). This is not to say that all cultural groups experience the same things or relate to others in the same way. But considerable overlap does exist between the models of different groups - especially by those who have the shared experiences with oppression - so the R/CID addresses this overlap. The R/CID comprises five stages - conformity, dissonance and appreciating, resistance and immersion, introspection, and integrative awareness (Sue \& Sue, 2013). These stages, outlined in Table 1.1, show how an individual develops a sense of identity as they encounter new information and experiences of cultural differences over time.

\begin{tabular}{|c|c|c|c|c|}
\hline Stages of Development & Attitude Toward Self & $\begin{array}{c}\text { Attitudes Toward } \\
\text { Others of Same } \\
\text { Race/Ethinicty/Culture } \\
\end{array}$ & $\begin{array}{c}\text { Attitudes Toward Others } \\
\text { of a Differrent } \\
\text { Race/Ethnicity/Culture }\end{array}$ & $\begin{array}{l}\text { Attitudes Toward } \\
\text { Dominant Group }\end{array}$ \\
\hline Stage 1 - Conformity & $\begin{array}{l}\text { Self-depreciating or neutral } \\
\text { due to low race salience }\end{array}$ & $\begin{array}{l}\text { Group-depreciaiton or neutral } \\
\text { due to low race salience }\end{array}$ & Discriminatory or neutral & Group-appreciating \\
\hline Stage 2 - Dissonance & $\begin{array}{l}\text { Conflict between self- } \\
\text { depreciating and group- } \\
\text { depreciating }\end{array}$ & $\begin{array}{l}\text { Conflict betwen group- } \\
\text { depreciating views of cultural } \\
\text { heirarchy and feelings of shared } \\
\text { experience }\end{array}$ & $\begin{array}{l}\text { Conflict between dominant- } \\
\text { held and group- } \\
\text { depreciating }\end{array}$ & $\begin{array}{l}\text { Conflict between group- } \\
\text { appreciating }\end{array}$ \\
\hline $\begin{array}{l}\text { Stage } 3 \text { - Resistance } \\
\text { and Immersion }\end{array}$ & Self-appreciating & $\begin{array}{l}\text { Group-appreciating experiences } \\
\text { and feelings of culturocentrism }\end{array}$ & $\begin{array}{l}\text { Conflict between feelings of } \\
\text { empathy for cultural others }\end{array}$ & Group-depreciating \\
\hline Stage 4 - Introspection & $\begin{array}{l}\text { Concern with basis of self- } \\
\text { appreciation }\end{array}$ & $\begin{array}{l}\text { Concern with nature of } \\
\text { unequivocal appreciation }\end{array}$ & $\begin{array}{l}\text { Concern with ethnocentric } \\
\text { basis for judging others }\end{array}$ & $\begin{array}{l}\text { Concern with basis of } \\
\text { group-depreciation }\end{array}$ \\
\hline $\begin{array}{l}\text { Stage } 5 \text { - Integrative } \\
\text { Awareness }\end{array}$ & Self-appreciating & Group-appreciating & Group-appreciating & Selective appreciation \\
\hline
\end{tabular}

Source: Sue \& Sue (2013), Mio et. al. (2012)

In the conformity stage, BIPOC individuals may exhibit strong preference for the beliefs, values, and features of the dominant group over their own, even if those dominant beliefs are negative toward their own racial/cultural heritage. In the United States, White Americans represent this dominant group. However, when presented with information that contradicts the values of the 


\section{A TALE OF TWO NARRATIVES}

dominant group, the BIPOC individual may move into the dissonance stage. In this stage, the individual may start to appreciate aspects of their own racial/cultural heritage and question those of the dominant group. These attitudes can be reinforced by hearing other members of their race/ethnicity talk about their own similar experiences with White individuals, such as racism, discrimination, and oppression. As the distrust between themselves and the dominant group grows, the individual will move into the resistance and immersion stage. Here, the individual tends to immerse themselves in the views held within their own community of color and rejects the dominant views of society. This stage is coupled with high amounts of guilt, shame, and anger, and feelings of being 'brainwashed' by White society (Sue \& Sue, 2013). These feelings are also commonly found in racial dialogue when stories are met with White resistance (Sue, 2013; Bell, 2003; Srivastava \& Francis, 2006). After a while, the BIPOC individual may find that holding on to these intense feelings is psychologically damaging and, as a result, can start to feel discontented with the rigid group views of the resistance and immersion stage. Neither of these experiences allows the individual time or energy for self-exploration, so it is upon this realization that he or she will move on to the introspection stage. Here, the individual experiences greater autonomy and may even find ways to incorporate both dominant and cultural heritage values into their identity. Only when the individual finds an inner sense of security can they advance to the final development stage: integrative awareness. It is here that the individual can fully appreciate the unique aspects of both their own cultural heritage and that of U.S. culture (Sue \& Sue, 2013).

Through these stages we can see how an individual, particularly those of marginalized groups, develops their identity over time and relates to the world at each stage. Even though this model can also apply to White individuals, the White Identity Model, developed Helms (1984), 


\section{A TALE OF TWO NARRATIVES}

provides a more specific understanding of identity development for White individuals,

particularly in terms of forming an anti-racism identity, and acknowledges their position of power in the U.S.

Like the R/CID above, the White Identity Model shows how a White individual develops a sense of identity over time. This model comprises six stages: contact, disintegration, reintegration, pseudo independence, immersion/emersion, and autonomy. Figure 1 outlines these stages.

Figure 1. White Identity Development Model

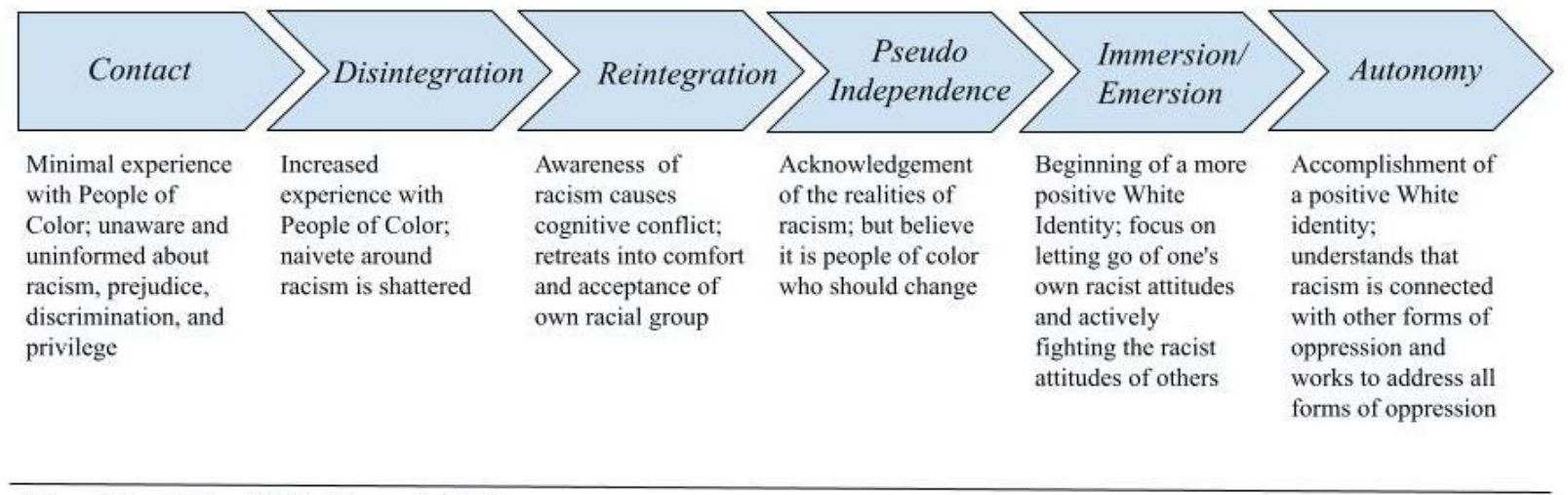

Adapted from Helms (1984), Mio et. al. (2012).

In the contact stage, White people are uniformed, and even often unaware, of the realities of prejudice, discrimination, racism, and privilege. Being in the dominant culture, they see themselves as the default and are often not even aware of themselves as racial beings (DiAngelo \& Sensoy, 2014; McIntosh, 1989). In this stage, the White individual may have limited experience with BIPOC communities, and cling to a colorblind ideology, making statements such as "People are people", "I don't see color", and "We're all the same under our skin" (Mio et. al., 2012, p. 210). These statements and corresponding ideologies were all commonly reported 


\section{A TALE OF TWO NARRATIVES}

themes across several racial dialogue studies (Bell, 2003; Sue, 2013; Miller \& Donner, 2000). It is not until one gains exposure to those of different races/ethnicities that they can move on to the second stage: disintegration. Here, the White individual's previously held beliefs are challenged and their naïveté around prejudice, discrimination, racism, and privilege starts to break down. White people easily buy into the dominant narrative, which places their race as superior to People of Color. In this stage, the White individual's interactions with People of Color contradict this narrative and their previously held beliefs which can lead to internal conflict or dissonance. In response to this challenge, Helms (as cited in Mio et. al., 2012) believes that a White individual will then shift to reintegration, in which the individual will "retreat to the comfort and acceptance of their own racial group" (p. 211). These three stages help to explain why stories in racial dialogue are met with such resistance. When one is blissfully unaware of the realities of others, a story to the contrary may feel like a threat to one's own sense of reality. It is easier, then, to deny these stories and seek safety under the status quo.

However, these stories may also help to bring about a new state of consciousness (Drew, 2012) and push White people into the fourth stage: pseudo independence. This marks the first step toward a nonracist White identity. In this stage, a White individual may start to acknowledge the existence of racism but believe it is People of Color who should change, imposing White standards in the name of "helping". After leaning into the discomfort of challenged beliefs and fully acknowledging the realities of racism, one may move into the immersion/emersion stage. Here, the White individual explores what it means to be "White" and starts to understand their privilege as well as their own role in the perpetuation of prejudice, discrimination, racism. They may start to actively fight the attitudes of others, focusing on changing others within the White community rather than People of Color. Eventually, the White 


\section{A TALE OF TWO NARRATIVES}

individual moves to the autonomy stage, marked by the construction of a positive White racial identity. In this stage, a White person finally feels comfortable in their own identity, finds interactions with racial others rewarding, and works to expand their sensitivity beyond racism by acknowledging their privilege and "act[ing] as allies who actively seek to combat discrimination" (Mio et. al., 2012, p. 212). Since this is often the goal of racial dialogue - to help White people move along these stages or development toward a positive anti-racist White identity - it is important to note that a single dialogue or story alone will not be sufficient to propel an individual into the autonomy stage. However, storytelling and dialogue may work as a form of 'exposure' in the process, especially in the earlier stages.

Understanding these stages of identity development, both for White people and People of Color, helps to understand how an individual might feel about themselves and interact with others. Where we are at in our racial identity development greatly affects our worldview. A Person of Color in the immersion stage may not understand how another Person of Color could work to appreciate and integrate aspects of dominant society (as in the integrative awareness stage). A White person in the contact stage, who claims to 'not see color', will not understand the world in the same way as a White person in the autonomy stage, who actively 'sees color' and works to fight against racism. And even across groups, a Person of Color in a later stage of development might find it harder to relate to a White person in an earlier stage of development,

and vice versa. These distinctions are important to understand and provide a possible explanation as to why counter narratives are met with such resistance in racial dialogue.

\section{Cognitive Dissonance}

As explored in the previous section, dissonance was a common occurrence for both White individuals and People of Color in their development of racial identity (disintegration and 


\section{A TALE OF TWO NARRATIVES}

dissonance stages respectively). I believe this particular aspect of development may hold important clues for understanding cognitive and emotional blockages during racial dialogue.

Cognitive dissonance is the all-too-common phenomenon that occurs when our behavior and beliefs do not align (McGrath, 2017). For example, in a recent study on the psychology of eating animals, Loughnan, Bastian, and Haslam (2014) found that many people regularly encounter the meat paradox. Not only do we care about (and care for) animals, we also simultaneously engage in consuming products that cause animal suffering and death. Becoming consciously aware of these contradictory views can cause great distress, so Cognitive Dissonance Theory states that one must either change their behavior (i.e., stop consuming animal products) or their beliefs (i.e., lessening the perceived capacity to suffer) to lessen the distress.

In the case of racism and racial dialogue, distress also ensues. When confronted with counter narrative, White people have two options: 1) accept the counter narrative as true, or 2) retreat into the comfort of the dominant narrative. The second option is easier, for if one were to accept counter narrative as truth, it means realizing that one has been complicit in the construction and maintenance of the current social hierarchies that perpetuate systems of inequality. This is disconcerting for White people because, as studies have shown, White people fear appearing racist, fear realizing their own racism and white privilege, and fear taking personal responsibility to end racism (Sue, 2013). Counter narrative challenges our worldview, so we often retreat into the dominant narrative to lessen the distress. Similarly, even though White Americans can easily identify racist behaviors in others, they have a hard time doing so in themselves and will consistently rate themselves as "less racist" than they actually are (Bell et. al., 2019). This asymmetry in perception - recognizing that racism exists yet failing to acknowledge one's own role in it - can foster a sense of cognitive dissonance and, ultimately, 


\section{A TALE OF TWO NARRATIVES}

create barriers when confronted with counter narratives (Sue, 2015). This is especially evident in color-blind ideology. In her study on racial storytelling, Bell (2003) reported that the strongest theme by White respondents was that of 'color-blindness', expressed in the common phrase 'I don't see color, I just see people'. This is a defining aspect of the first stage of White racial identity development. Frankenberg (1993) asserts that this ideology assumes that "seeing race means being racist and being racist means being 'bad"' (p. 147). The dominant narrative works to lessen this fear of 'badness' in White Americans by consistently positioning them as 'good' and 'fair', and "reassures them that, despite problems, ongoing social progress has been made" (Bell, 2003, p. 4).

When People of Color share narratives, they may also experience behavioral or ideological dissonance. Oftentimes People of Color are more concerned with whether their stories/messages will be believed and accepted and less so with how they themselves will be perceived by others. This can lead to individuals preventing themselves from sharing candidly or may result in them silencing their own voices. Sue (2015) points out that in higher education, students and teachers consistently feel the need to censor their emotions and communication styles in the classroom so that their actions will be received the right way. One way this could manifest is by People of Color softening, if you will, their stories or experiences in order to keep their White counterparts comfortable. In adjusting one's communication style or suppressing one's emotions as a way to ensure White listeners' comfort levels, this, regrettably, may result in BIPOC individuals feeling "less authentic" which can "result[s] in a nagging sense that they [have] sold out their integrity" (Sue, 2013, p. 667). This may cause them to experience cognitive dissonance as their behavior (i.e., censoring their behavior) does not align with their beliefs and values (i.e., integrity and authenticity). 


\section{A TALE OF TWO NARRATIVES}

Dissonance does not only occur by an inequality of beliefs and behaviors, dissonance can occur in identity as well (MacGrath, 2017). In the social sciences, research on African American experiences and family life seems to run on a comparison model, using a "White Standard" and a "Difference Equals Deficit" ideology. Using this kind of model is problematic in that it results in unrealistic representations and tends to present African American families as 'deficient' for deviating from the 'norm' (i.e., White families) (Allen, 1995). This view reinforces the larger, dominant White narrative (Trainor, 2005; Bell, 2003; McIntyre 1997). However, this also creates discrepancy between the narrative put forth by behavior and the actual experiences of African American families. As Carter-Black (2007) recounts:

As a child, many of the impressions I had of my family were gleaned from the plethora of stories I had heard from my earliest years. These stories conveyed African American families and indeed individual family members as heroes. We were told these heroes of our past and present, possessed a deep love for family and community, stamina, and unswerving determination to survive no matter what, and a commitment to God that was both unparalleled and the source of their seemingly unlimited inner strength in the face of overwhelmingly oppressive circumstances. Clearly, a dissonance existed between what was presented to us as the reality or truth of the Black family life from a culturallybased African American worldview and the empirically-based evidentiary conclusions reached by social scientists investigating African American families. (p. 37)

Here we can see how the dissonance between the dominant narrative and lived experiences can create emotional turmoil and hardship in the lives of People of Color. Not only can this lead to harmful internalized beliefs, but this misrepresentation can also lead to negative, harmful, and even dangerous interactions between White people and People of Color (Bell, 2003). Dialogue 


\section{A TALE OF TWO NARRATIVES}

practices should be mindful of these reactions and interactions when engaging participants in racial dialogue.

\section{Expectation and Reception}

Differences in worldview and identity development can also lead to differences in expectations when entering into racial dialogue. "White [people] are also more likely to view racial dialogues as a useful end in and of itself while People of Color are more apt to judge it according to whether or not it leads to action" (Miller \& Donner, 2000, p. 48). For People of Color, racism is nothing new. The counter narrative that they have formed expresses daily encounters with race and exposes the long enduring nature of racism. Even though sharing their stories may foster a sense of empowerment and validation, it is still done so with the intent to educate White people and bring about social change. For White people, on the other hand, racism is a supposed 'thing of the past'. They often do not see themselves as racial beings, therefore, neither do they have to do this for others. The dominant narrative that they have created allows them to remain in denial; they need not explore the realities of People of Color. So, for White people, listening to these stories and accepting counter narrative as truth is seen as a significant feat in itself since this practice goes against the dominant narrative and challenges the 'status quo'. This phenomenon seems to be common among intractable inter-group conflicts. In the Israeli/Palestine dialogic projects (also believed to be fueled by contradictions in historical narratives), this same difference in expectation manifested over time; Israelis were happy to continue the talks, but Palestinians craved tangible action (Rothman, 1997). This seems to be a highly influential factor among dialogue practices overall. It would be wise to be aware of potential differences in expectation and be clear about the overall goal of dialogue before starting. 


\section{A TALE OF TWO NARRATIVES}

These differences in expectation and reception can also lead to differences in perception of accomplishment. In a 2000 study, Miller and Donner found significant differences in the perceived effectiveness of racial dialogue among White students and Students of Color. Similarly, in assessing the effectiveness of the Restorative Listening Project, Drew (2012) also found that most White participants found a "new or deepened consciousness". While White people often leave a dialogue feeling good about themselves and optimistic for the future, People of Color often leave feeling emotionally drained and unsure whether the dialogue will lead to any kind of tangible change. Discrepancies are concerning, especially since these dialogues are often used as both a teaching tool and method of conflict resolution. Srivastava and Francis (2006) argue that this is because so many of these dialogues focus on the "authentic experience" of the tellers rather than directing attention to the systems, structures, and policies that work to keep racism in place. When too much attention is given to educating White people via stories, this reduces People of Color to simply being 'sources of knowledge' and puts them "in the position of defending, reasserting, and reinforcing their identities" (Srivastava \& Francis, 2006, p. 301). This not only puts an emotional strain on the storytellers, but also adds to the growing divide of hope for the future. If both parties are entering with differing expectations and then leaving with different feelings of accomplishment, the overall effectiveness of these dialogues and the specific use of storytelling - is put into question.

\section{Discussion}

\section{Narratives as a Learning Tool}

The conflict between dominant and counter narrative is ultimately paradoxical. Not only do these narratives shape our worldviews and racial identities, but when we bring them both into racial dialogue, these narratives may also cause blockages in communication and may detract 


\section{A TALE OF TWO NARRATIVES}

from the quest for real social change. While many argue for the use of storytelling as a tool to understand and combat racism (Carter-Black, 2007; Senehi, 2002; Drew, 2012), others are hesitant, since it has the potential to increase tension and enact a heavy toll on the tellers (Srivastava \& Francis, 2006; Sue, 2013; Sue, 2015). I believe that storytelling does possess the ability to bridge differences and create change but combating these potential side effects requires careful integration of storytelling into these dialogues. First, it is important to honor the narratives of People of Color. It is crucial to remind participants that while their stories are vitally important, People of Color are not simply sources of information, nor are they merely representatives of their whole community or culture. Their stories hold great historical, cultural, and personal significance, and may even be key to their survival. As Gates (1989) states: “Telling ourselves our own stories - interpreting nature of our world to ourselves, asking and answering epistemological and ontological questions in our own voices - has as much as any single factor been responsible for the survival of the African-Americans and their culture" (p. 17). Counter narratives play a vital role in the dismantling of racism, but they are only one strategy for enhancing awareness and understanding; multiple means must be used to instill a commitment to actual change be it personal growth or systemic paradigm shifts. While enhancing our awareness of others' experiences is critical, we must also develop greater insight into our own personal beliefs and cultural identities and how we experience obstacles to connecting to and empathizing with others' [counter] narratives.

\section{Acknowledging Our Potential 'Baggage'}

As I've explored above, differences in worldview and where one is at in their identity development could lead to difficulties in navigating the expectations and reception of racial dialogue. We bring these differences with us into the dialogue, often unconsciously. Priming 


\section{A TALE OF TWO NARRATIVES}

participants (i.e., making participants aware of their own worldviews and racial identities beforehand) could help to mitigate ignorance and accelerate the process of shared understanding. This is especially true for White people. As Drew (2012) states: "one of the most complicated yet necessary - approaches for developing antiracist white consciousness is to name the mechanisms in place that prevent White people from deeply listening and often keep them willfully ignorant” (p. 112). By understanding how the dominant narrative shapes one's worldview (and thus, one's ignorance), we as White people can understand the 'baggage' we hold and how it keeps us from seeing the bigger picture: the possibility of a shared narrative one that is inclusive of multiple voices.

\section{Focus on Inclusive Narratives}

Another thing I'd like to point out is the possibility of a shared identity. The current narratives are at odds; one works to keep White people cloaked in air of ignorance while the other works to dissolve that ignorance. To remedy this, it would be wise to shift the narrative to one in which 1) racial identities are in line with lived experiences; and 2) honors racial acknowledgement (i.e., 'seeing racism' does not mean 'being bad'). The goal should not only to ensure lasting social change but to make sure narratives are inclusively integrated as well, understanding that all are of equal value and importance. Inclusivity of diverse narratives helps to reinforce a social justice focus. Senehi (2002) makes the argument that "in the case of longstanding intercommunal conflicts, developing a shared historical narrative may be a means for bridging conflict and developing a shared identity that encompasses diversity without erasing it" (p. 49). Rothman (2015) also proposes the idea of a shared narrative, claiming that this 'meshing' of stories could help pave the way for constructive cooperation, especially in conflicts that are rooted in historical turmoil (pp. 25-26). Even though creating a shared identity may be a long and 


\section{A TALE OF TWO NARRATIVES}

dynamic process for race relations in the U.S., it is not impossible. This 'shared identity' is not meant to be suggestive of a single race or colorblind ideology, but rather a shared identity of nation and community, one in which all people - regardless of race - share power, privilege, and belonging. These identities - be it race, ethnicity, gender, sexual orientation, nationality, or any other form of identity - are nestled uniquely within each human so it is, at the very least, possible to create a narrative that acknowledges pieces in all of us. Moving toward more inclusive narratives, however, is merely one next step. There are additional efforts that should be undertaken to ensure continued growth and enhanced awareness.

\section{Self-Reflection}

As a researcher/author who identifies as White, it is important to acknowledge that - just as in dialogue - I am bringing my own worldview, identity, and privilege into this analysis. I recognize that this may 'color' my perspective around race and racism, and I urge readers to understand this as well. While I continuously work to reshape this worldview and identity, privilege has still brought me to the point of writing this paper. As a transgender individual, I may in some ways be familiar with the systems that work to perpetuate oppression, but I will never know what it is like to be a Person of Color. It was important that any research I cited regarding People of Color specifically came from researchers of color or from first-hand testimony directly. Coming from predominantly White communities, I have seen first-hand the lengths to which White people will go to stay within their comfort zone and deny the realities of racism, myself included. It is my hope that this research will not only help to strengthen future dialogue practices but also help White people like myself to uncover our 'baggage' and work to address the baggage in those around us. Conducting this research has helped me to understand the role I play in the perpetuation of racism. For example, engaging with these studies and testimonies has given me a 


\section{A TALE OF TWO NARRATIVES}

deeper appreciation for the cultural, historical, and personal importance that stories hold for People and Color. And made me recognize that it is within my power to remind others of this importance as well. Additionally, before conducting this research I, too, harbored the mentality that simply listening to these stories and accepting counter narrative as truth was a big deal. But, I now realize that this is not the case and that my perception of why we engage in these dialogues was flawed. It is not for my education or benefit, but rather for betterment of marginalized groups and creating actionable change. In any future studies, it is critical that researchers acknowledge how their cultural identities, worldview and experiences with privilege and/or oppression shape the lens through which they analyze theories and data as these may prevent them from examing racism and other forms of discrimination in a comprehensive and holistic manner.

\section{Future Recommendations}

While this paper has discussed the ways in which identity development, worldview, cognitive dissonance, and power/privilege can shape one's reactions to dialogue around race and racism, future papers should also examine potential skill sets and additional knowledge that can better equip White people to effectively engage and empathize with the narratives of People of Color and other historically marginalized groups. For instance, DiAngelo's (2011) concept of White Fragility can help White individuals better understand why they may become defensive and strive to avoid discussions when they become uncomfortable (i.e., challenge one's worldview and the dominant White narrative). The concept of microaggressions (Sue et. al., 2007) and understanding how these can manifest, often unintentionally, in the behavior of those who come from privilege groups, including White people, might also be helpful. Understanding how intersectionality (i.e., how our multiple cultural identities and backgrounds simultaneously 


\section{A TALE OF TWO NARRATIVES}

shape our lens as well as affect how others treat us) can help one come to terms with one's privilege and the oppression of others. Lastly, examining the ways in which cultural humility (DiAngelo and Sensoy, 2014) and cultural competence (Mio et. al., 2012) may be effectively achieved through the use of inclusive narratives along with other strategies would also be important.

It should also be noted that the experiences of People of Color in America - whether Black, Brown, Asian, Hispanic, Indigenous, etc. - are extremely varied and nuanced, each with their own cultural artifacts and daily experiences. Future research should look more closely into more specific models beyond White Identity Development and R/CID (i.e., Black Identity Development; Chicano/Latino Identity Development; Asian/American/Pilipino American Identity Development; Multiracial Identity Development; etc.) to uncover additional layers of storytelling and overall worldview with respect to specific racial and ethnic identities.

\section{Conclusion}

In this paper, I focused on two identity groups - White people and People of Color. While examining conflict from these two identity perspectives was helpful, it is still important to note that each racial/ethnic group tends to have its own unique experiences with race and racism. More research is needed to understand these nuances, and dialogue practices should be mindful of these nuances when using storytelling in their dialogues.

In this paper I have examined the relationship between storytelling and racial dialogue and provided possible explanations as to why stories are met with such resistance in racial dialogues. Theories on identity development, worldview, cognitive dissonance, and power/privilege were applied to overall storytelling and racial dialogue practices. Through this analysis I have attempted to show how stories help to shape how we view the world, and in 


\section{A TALE OF TWO NARRATIVES}

return, how that worldview also shapes how we receive the stories of others. It is my hope that by understanding the role that storytelling plays in shaping how we see the world, we may be able to integrate storytelling more carefully into racial dialogues, and thus make these dialogues more effective, ultimately leading to more permanent social and systemic change. 


\section{References}

Allen, W. R. (1995). African American family life in societal context: Crisis and hope. Sociological Forum, 10, 569-592.

Bauman, R., \& Charles, B. L. (1990) Poetics and performance as critical perspectives on language and social life. Annual Review of Anthropology, 19, 59-88.

Bell, A. C., Burkley, M., \& Bock, J. (2019). Examining the asymmetry in judgments of racism in self and others. The Journal of Social Psychology, 159(5), 611-627.

Students consistently evaluated themselves more racist than the "other", even though the behavior they were evaluating was their own. A common method of reducing cognitive dissonance is denial of responsibility, an unwillingness to see our own behavior as the problem.

Bell, L. A. (2003). Telling tales: What stories can teach us about racism. Race Ethnicity and Education, 6(1), 3-28. https://doi.org/10.1080/1361332032000044567

These stories showed central themes in POC narratives (i.e. personal danger and vulnerability in White settings, differential treatment in public arenas, attacks on one's self worth and dignity, as well as White Blindness, intensity and cruelty).

Carter-Black, J. (2007). Teaching cultural competence: An innovative strategy grounded in the universality of storytelling as depicted in African and African American storytelling traditions. Journal of Social Work Education, 43(1), 31-50.

DiAngelo, R. (2011). White fragility. International Journal of Pedagogy, 3(3), 54-70. 
DiAngelo, R. J. (2004). Whiteness in racial dialogue: A discourse analysis (Publication No. 3131146) [Doctoral Dissertation, University of Washington]. ProQuest Information and Learning Company.

DiAngelo, R. J. \& Sensoy, O. (2014). Calling in: Strategies for cultivating humility and critical thinking in antiracism education. Understanding and Dismantling Privilege, 4(2), 191201.

Drew, E. M. (2012). "Listening through White Ears": Cross-racial dialogues as a strategy to address the racial effects of gentrification. Journal of Urban Affairs, 34(1), 99-115. https://doi.org/10.1111/j.1467-9906.2011.00572.x

Frankenberg, R. (1993) White Women, Race Matters: the social construction of Whiteness. University of Minnesota Press.

Gates, H. L. (1989). Ethnographic methods: Applications from developmental cultural psychology. In L. Goss \& M. E. Barnes (Eds.), Talk that talk: An anthology of AfricanAmerican storytelling (pp. 15-19). New York: Simon \& Schuster.

Gurin, P., Nagda, B. R. A., \& Zúñiga, X. (2013). Dialogue across difference: Practice, theory, and research on intergroup dialogue. Russell Sage Foundation.

Helms, J. E. (1984). Toward a theoretical explanation of the effects of race on counseling: A Black and White model. The Counseling Psychologist, 13, 695-710. 


\section{A TALE OF TWO NARRATIVES}

Loughnan, S., Bastian, B., \& Haslam, N. (2014). The psychology of eating animals. Current Directions in Psychological Science, 23(2), 104-108. https://doi.org/10.1177/0963721414525781

Maines, D. (2000). The social construction of meaning. Contemporary Sociology, 29(4), 577584. doi:10.2307/2654557

McGrath, A. (2017). Dealing with dissonance: A review of cognitive dissonance reduction. Social and Personality Psychology Compass, 11(12), e12362.

In basic understanding of cognitive dissonance, we can see how discrepancies between one's beliefs and one's behaviors can create significantly unpleasant feelings, especially when it comes to communal ideologies. To overcome this paradox, one must either change their beliefs or their behaviors; the severity of the dissonance will dictate the severity of the adjustment. Believing in a just world while simultaneously being cognizant of racism can lead to cognitive dissonance, and could be a possible explanation for strong, widespread resistance to racial dialogue.

McIntosh, P. (1989). Whiter privilege: Unpacking the invisible knapsack. In A. M. Filor (Ed.), Multiculturalism (pp. 30-36). New York State Council of Educational Associations.

McIntyre, A. (1997) Making meaning of whiteness. State University of New York Press, Albany. Miller, J., \& Donner, S. (2000). More than just talk: The use of racial dialogues to combat racism. Social Work With Groups, 23(1), 31-53. https://doi.org/10.1300/J009v23n01_03

Mio, J. S., Barker, L. A., Tumambing, J. S. (2012). Multicultural psychology: Understanding our diverse communities (3rd ed.). Oxford University Press. 


\section{A TALE OF TWO NARRATIVES}

Nagda, B. (Ratnesh) A., \& Gurin, P. (2007). Intergroup dialogue: A critical-dialogic approach to learning about difference, inequality, and social justice. New Directions for Teaching and Learning, 2007(111), 35-45. https://doi.org/10.1002/t1.284

Native American legends: Coyote (West Coast and Northwestern). (n.d.). Native Languages of the Americas. Retrieved August 4, 2021, from http://www.native-languages.org/westcoast-coyote.htm

Rothman, J. (1997). Resolving identity-based conflict in nations, organizations, and communities. San Francisco: Jossey-Bass Inc.

Rothman, J. (2015) A new view on the Israeli-Palestinian conflict: From needs and narratives to negotiation. Middle Eastern Politics \& Culture, 15.

Senehi, J. (2002). Constructive storytelling: A peace process. Peace and Conflict Studies, 9(2), 40-63.

Srivastava, S., \& Francis, M. (2006). The problem of `authentic experience': Storytelling in antiracist and anti-homophobic education. Critical Sociology, 32(2-3), 275-307. https://doi.org/10.1163/156916306777835330

Sue, D. W. (2013). Race talk: The psychology of racial dialogues. American Psychologist, 68(8), 663-672. http://dx.doi.org.proxy.lib.pdx.edu/10.1037/a0033681

Sue, D. W. (2015). Race talk and the conspiracy of silence: Understanding and facilitating difficult dialogues on race. John Wiley \& Sons, Incorporated. 


\section{A TALE OF TWO NARRATIVES}

Provides a foundation to the question "Why is it so hard for white people to talk about race?" Chapter 8 discusses the actions of Cognitive Avoidance, Emotional Avoidance, and Behavioral Avoidance when white people are confronted with race. All three are possible outcomes of cognitive dissonance.

Sue, D. W., Capodilupo, C. M., Torino, G. C., Bucceri, J. M., Holder, A., Nadal, K. L., \& Esquilin, M. (2007). Racial microaggressions in everyday life: implications for clinical practice. American psychologist, 62(4), 271.

Sue, D. W., Lin, A. I., Torino, G. C., Capodilupo, C. M., \& Rivera, D. P. (2009). Racial microaggressions and difficult dialogues on race in the classroom. Cultural Diversity and Ethnic Minority Psychology, 15, 183-190. doi:10.1037/a0014191

Sue, D. W., Rivera, D. P., Watkins, N. L., Kim, R. H., Kim, S., \& Williams, C. D. (2011). Racial dialogues: Challenges faculty of color face in the classroom. Cultural Diversity and Ethnic Minority Psychology, 17, 331-340. doi:10.1037/a0024190

Sue, D. W., \& Sue, D. (2013). Counseling the culturally diverse: Theory and practice. John Wiley \& Sons, Inc.

Trainor, J. S. (2005). “My ancestors didn’t own slaves”: Understanding White talk about race. Research in the Teaching of English, 40(2), 140-167. 